\title{
Correction to: On generalized Rubel's equation
}

\author{
S. S. LINCHUK AND Yu. S. LINCHUK
}

Correction to: Aequat. Math. https://doi.org/10.1007/s00010-017-0467-x

In the original publication linking to CrossRef, MATH, MathSciNet were missed for the References [9-12]. The correct References are given below.

\section{References}

[9] Linchuk, Yu.S: On Rubel's problem in the class of linear operators on the space of analytic functions. Complex Anal. Oper. Theory 8, 1741-1745 (2014). https://doi.org/ 10.1007/s11785-014-0366-2

[10] Linchuk, Yu.S: On an operator analog of the cosine addition theorem. J. Math. Sci. 200, 345-351 (2014). https://doi.org/10.1007/s10958-014-1916-x

[11] Linchuk, Yu.S: On derivation operators with respect to the Duhamel convolution in the space of analytic functions. Math. Commun. 20, 17-22 (2015). http://hrcak.srce. $\mathrm{hr} / 140384$ ?lang=en

[12] Linchuk, S.S., Linchuk, Yu.S: A description of derivation operators with respect to convolution of generalized Gelfond-Leontev integration. Fract. Calc. Appl. Anal. 18, 972-981 (2015). https://www.degruyter.com/view/j/fca.2015.18.issue-4/ fca-2015-0057/fca-2015-0057.xml

The original article can be found online at https://doi.org/10.1007/s00010-017-0467-x. 
S. S. Linchuk and Yu. S. Linchuk

Department of Mathematical Analysis

Chernivtsi National University

Kotsjubyns'koho 2

Chernivtsi 58012

Ukraine

e-mail: nesslin.new@gmail.com

Yu. S. Linchuk

e-mail: yustlin@gmail.com 